\title{
HISTORY OF SCIENCE OF KARAKALPAKSTAN OF THE XX CENTURY
}

\author{
Temirkhanov Baxtiyar \\ Karakalpak Scientific Research Institute of Humanities \\ Karakalpak Branch of the Academy of Sciences of the Republic of Uzbekistan
}

Article DOI: https://doi.org/10.36713/epra8501

DOI No: 10.36713/epra8501

\begin{abstract}
The article is devoted to the history of the formation and development of science in Karakalpakstan. It is stated that in 1931 the Karakalpak Integrated Research Institute was established in Turtkul. In the pre-war period, this institute was reorganized several times, as a result of which difficulties arose in coordinating scientific and research work in Karakalpakstan. In 1947, it was transferred to the Academy of Sciences of Uzbekistan. In 1959, the Karakalpak affiliate of the Academy of Sciences of the Uzbek Soviet Socialist Republic was organized on the basis of the Karakalpak Integrated Research Institute, which made it possible to coordinate and develop fundamental scientific research in the republic. The scientists focused on topical issues of the development of the economy and culture of the republic, in particular, the study of natural resources, material and spiritual culture of the Karakalpak people. The author claims that a new stage in the development of this scientific center begins in 1991, when the Karakalpak affiliate of the Academy of Sciences of the Republic of Uzbekistan receives the status of the Karakalpak branch. The author critically assesses the period of development of science in Karakalpakstan in the 1990s, while claiming that this scientific institution has risen to new stages of its development and certain achievements have been achieved.
\end{abstract}

KEYWORDS. Science; history; scientific expeditions; Karakalpak Scientific Research Institute; reorganization; integrated institute; affiliate, branch; scientific research; department; prospects.

\section{INTRODUCTION}

The history of the formation and state of science, its structural development is studied by a discipline called science studies. This is a field of research that studies the laws of the functioning and development of science, the structure and dynamics of scientific work, the interaction of science with state and other social institutions and spheres of the material and spiritual life of society.

The history of science or science studies is an important part of scientific and empirical research. Science itself is a set of theoretical and practical knowledge about the surrounding world, obtained by specialist scientists. It represents objective knowledge about the surrounding world, at the same time it is the process of obtaining and using this knowledge by society, the organization of scientific activities and scientific institutions.

The relevance of the topic of our research is to develop the historical foundations of the organization, planning and management of science in Karakalpakstan in the XX century. Scientific interest in the topic is characterized by the objective logic of the development of science in modern Uzbekistan, due to the pace of its development in the world and the need to improve the effectiveness of scientific research

\section{MATERIALS AND METHODS}

The history of science of Karakalpakstan is an almost unexplored page in the national history; however, a lot of information about the organization of scientific activities in the territory of Karakalpakstan has been preserved in the scientific literature. As known, the first scientific expeditions were carried out in 1926-1930, when groups of students from Tashkent and Moscow repeatedly came to Karakalpakstan to study the history, language and culture of the Karakalpaks. These groups received all the support of the local authorities [1].

As K.Aymbetov recalls, in 1928 and 1930 the head of the Karakalpak expedition of the Society for the Study of Kazakhstan A.L.Melkov arrived, and also N.A.Baskakov and A.S.Morozova worked here. 
In 1930 professor S.E.Malov arrived, also the famous professor A.A.Sokolov, who, after K.Nurmukhamedov's speech to the Central Executive Committee of the Russian Soviet Federative Socialist Republic, organized a scientific expedition in the Chimbay and Takhtakupyr districts in 1933 [2].

From that moment, the general composition of the science of Karakalpakstan, the means and forms of its functioning began to form. It is important to note that scientific activity had a close connection with the political, economic and socio-cultural transformations in the Karakalpak society. It is impossible not to take into account the dependence of the pace and directions of its development on other social phenomena and institutions.

The main methods of working on the topic are the problem-thematic approach, which allows us to identify a socially significant problem that was tracked in a number of publications for a certain time period. One of the most popular in the course of the study was the comparative-historical method used to compare single-topic materials and identify the dynamics of changes that occurred in the field of science and scientific activity.

During the period under study, the science of Karakalpakstan functioned under the conditions of Soviet rule and the years of national independence of the Republic of Uzbekistan. This creates conditions for the application of an interdisciplinary approach that includes the entire range of research methods of the humanities, allowing us to consider a set of interrelated and interacting objects, taking into account a wide historical context, a variety of sociopolitical structures and economic institutions.

\section{RESULT AND DISCUSSION}

According to the resolution of the Council of People's Commissars of the Karakalpak Autonomous Soviet Socialist Republic, in August 1931, the first scientific institution in Karakalpakstan was organized - the Karakalpak Integrated Research Institute. It was located in the building of a former church in Turtkul. The first director of the Karakalpak Integrated Research Institute was appointed A.A.Gnedenko, who in 1930 was sent to the Karakalpak Autonomous Soviet Socialist Republic for a permanent job. The institute includes sections of history, soil-desert-sand, economic research, methods and planning of mass local history work, an entomology office, a hydro meteorological bureau, a chemical laboratory, as well as a scientific and terminological section of the department of public education, a local history museum, a department of the history of the regional archive, etc.

In 1932, a large-scale expedition of the Union of Soviet Socialist Republics Academy of Sciences took place on the territory of Karakalpakstan, the results of which were discussed at the 1st conference on the study of the productive forces of the Karakalpak Autonomous Soviet Socialist Republic in March 1933 in Leningrad (now St. Petersburg).

The organization of this research expedition gave a huge impetus to the development of science in Karakalpakstan. On June 29, 1932, the Council of People's Commissars of the Karakalpak Autonomous Soviet Socialist Republic proposed to allocate funds for the organization of a chemical laboratory at the Karakalpak Scientific Research Institute [3]. At the end of the expedition, it was proposed to transfer the Karakalpak Scientific Research Institute to the Union of Soviet Socialist Republics Academy of Sciences. On August 29, 1932, the Council of People's Commissars of the Karakalpak Autonomous Soviet Socialist Republic heard a report by A.A.Gnedenko "On strengthening scientific research in the Karakalpak Autonomous Soviet Socialist Republic”. In the resolution on this issue, it was decided to "enter with a petition to the Presidium of the Union of Soviet Socialist Republics Academy of Sciences on the transfer of the Academy of Sciences of the Karakalpak Scientific Research Institute of the Karakalpak Autonomous Soviet Socialist Republic, retaining the direction and the name "Integrated Research Institute of the Union of Soviet Socialist Republics Academy of Sciences in the Karakalpak Autonomous Soviet Socialist Republic" with the following sections: a) geological; b) socio-cultural; c) economic research; d) soil-geo botanical; e) desertsandy; f) physical-chemical laboratory" [4]. At the same time, it was decided to convene a scientific conference on the study of the productive forces of the Karakalpak Autonomous Soviet Socialist Republic with the involvement of the country's leading scientists.

In October 1933, it was proposed to organize a popular scientific journal of the Karakalpak Scientific Research Institute, at the meeting of the Council of People's Commissars of the Karakalpak Autonomous Soviet Socialist Republic on September 9, 1933, an editorial board was formed (D.Loginov, Tetyushev, K.Bazhakov, A.Kulenov, Gavrilin, Yakubov, Ismukhamedov). A month later, the composition of the board was changed and it was approved as part of Tetyushev (executive secretary), Aimbetov, Dzhaksymuratov, Isamukhamedov, Karp, Kulenov, Loginov, Sokolov, Yakubov [5].

In 1934, the situation changed and scientific activity was gradually curtailed. According to the resolution of the Council of People's Commissars of the Karakalpak Autonomous Soviet Socialist Republic, on March 15, 1936, the Karakalpak Scientific Research Institute was reorganized and a scientific group was formed under the State Planning Committee [6]. Subsequently, V.Efanov's article "We need a research institute" indicated that the 
reorganization, "and in essence the liquidation of the Karakalpak Scientific Research Institute did not give positive results" [7]. The dispersal of the control levers over scientific research and search operations did not give a practical effect. The formation of a single center for the management and coordination of research activities in Karakalpakstan was urgently required.

In 1939, the Karakalpak Scientific Research Institute of Language, Literature and History was organized as one of the sectors in the system of the People's Commissariat of Education of the Karakalpak Autonomous Soviet Socialist Republic, but with the beginning of the Second World War, the institute was inactive [8]. On September 27, 1943, it was decided to form the Academy of Sciences of the Uzbek Soviet Socialist Republic on the basis of the Uzbek affiliate of the Union of Soviet Socialist Republics Academy of Sciences. According to the decree of the Presidium of the Supreme Soviet, the Council of People's Commissars of the Uzbek Soviet Socialist Republic and the Central Committee of the Communist Party (b) of the Uzbek Soviet Socialist Republic, the opening was scheduled for November 4, 1943. In March 1944, the Karakalpak Scientific Research Institute of Language, Literature and History under the Council of Ministers of the Karakalpak Autonomous Soviet Socialist Republic resumed its work [9]. Although at that time the institute did not have its own premises, equipment, or scientific personnel.

On July 26, 1947, the resolution of the Council of Ministers of the Uzbek Soviet Socialist Republic No. 1179 was adopted on the transfer of the Karakalpak Scientific Research Institute of Language, Literature and History under the Council of Ministers of the Karakalpak Autonomous Soviet Socialist Republic to the Academy of Sciences of Uzbekistan. On September 24, 1947, a positive decision was made by the Presidium of the Academy of Sciences of the Republic and this institute was transformed into an independent scientific institution - the Karakalpak Scientific Research Institute of Economics and Culture. In 1948, 4 candidates of sciences and 4 researchers with higher education worked at the Institute.

In 1959, the Karakalpak affiliate of the Academy of Sciences of the Uzbek Soviet Socialist Republic was organized on the basis of the Karakalpak Integrated Research Institute, which made it possible to coordinate fundamental scientific research in the republic. The topics of scientific works covered almost the entire range of branches of the national economy. Academic publications on the history of Karakalpakstan, the Karakalpak language and literature were published; a 20-volume book of "Karakalpak folklore" was published. The Institute of History, Language and Literature has begun to work on the collection and introduction into scientific circulation of written monuments, which are an invaluable spiritual value of the people.

The most important scientific problem raised by scientists of the Karakalpak affiliate of the Academy of Sciences of the Uzbek Soviet Socialist Republic was the Aral ecological disaster. Back in the mid-1970s, scientists very sharply raised the question of the need to save the Aral Sea, justifying it from an economic point of view. Doctor of Biological Sciences R.Tleuov in the mid-1970s wrote that it is difficult to predict all the consequences of the drying of the Aral Sea and pointed out the possibility of reducing the humidity of the air and soil, increasing the harmful influence of winds. He then foresaw that "as a result of the drying of the Aral Sea, huge masses of salts will be carried away by the wind to the plains of Central Asia and Kazakhstan, 20 million hectares of land will be salted". He also assumed that the impact of the drying up of the Aral Sea would be felt on all aspects of the economy of the republics of Central Asia and Kazakhstan, on the climatic and natural conditions of the Aral Sea basin. To solve the problem of the sea, he proposes to widely adopt "agro technical measures in the basins of the Amu Darya and the Syr Darya aimed at obtaining products at lower water costs, establishing a minimum flow pass necessary for the development of the economy and maintaining water losses for evaporation by lacing the delta reservoirs and collapsing the Amu Darya and the Syr Darya spills and using underground run off" [10].

The well-known scientist, Doctor of Biological Sciences S.Kabulov considered the problem much more broadly. Assessing the problem of the Aral Sea as a complex one, he advocated a comprehensive analysis of both the problem itself and the consequences arising from it. "The drying up of the Aral Sea will be accompanied by a violation of the balance in the nature of Central Asia", he argued. S.Kabulov makes excursions into history, justifying the need to take into account, first of all, the human factor. "The peoples who inhabited these places in ancient times, unlike the steppe Saks, were called Apasiaks, i.e. marsh or water Saks", the natural balance was established not yesterday, it has existed for thousands of years [11].

In general, in the 1970s, advanced scientific thought actively advocated the salvation of the Aral Sea, offering new forms and methods of managing water resources. The struggle for saving the Aral Sea was not only at the level of scientifically based recommendations, but also publications in the periodical press. In the second half of the 1970s, in connection with the resuscitation of the issues of the transfer of northern rivers to Central Asia and Kazakhstan, advanced scientific thought was able to 
bring the complexity of the environmental situation to the public more widely.

The proclamation of the national independence of the Republic of Uzbekistan has become a new stage in the development of science in Karakalpakstan. In 1991, the Karakalpak affiliate of the Academy of Sciences of the Republic of Uzbekistan was transformed into the Karakalpak branch. Chairman of the Presidium of the Karakalpak Branch of the Academy of Sciences of Uzbekistan S.Kamalov argued that "with the acquisition of the status of sovereign states, the Academy of Sciences of the Republic of Uzbekistan has become an independent, self-governing organization operating on the basis of the laws of the Republic of Uzbekistan and its own Charter. The organization of the Karakalpak branch of the Academy of Agricultural Sciences of the Republic of Uzbekistan is gratifying" [12].

As part of the Karakalpak Branch of the Academy of Sciences of the Republic of Uzbekistan, new institutes and divisions were organized, including the Integrated Institute of Natural Sciences, the Institute of Language and Literature named after N.Davkarayev, the Institute of History, Archeology and Ethnography, a Computing Center, a Botanical Garden, and a fundamental library. In 1992, the Scientific Research Coordination Center "Aral" was transferred to the Karakalpak branch by the decree of the Cabinet of Ministers under the President of the Republic of Uzbekistan and was formed as the Department of Environmental Problems of the Aral Sea region. A Fundamental library also functioned.

In 1992, 39 topics were developed in the institutes of the branch, including 34 fundamental, 5 search, and 17 contractual projects, and in the following 1993-50 fundamental topics [13]. In the following years, the scientists of the branch conducted their research annually on a budget basis, until the transition to a competitive basis in 2002.

\section{CONCLUSION}

The formation of a scientific center in Karakalpakstan in the early 1930s was a significant event in the life of the republic. All scientific research works were concentrated here, major scientists conducted their research, and a new generation of scientists from among local nationalities was formed.

In its development, the scientific center of Karakalpakstan has experienced several stages of reorganization, which were associated with socioeconomic phenomena. The process of science development in Karakalpakstan experienced its greatest development in the 1970s, when topical issues of economic and cultural development of the republic were actively studied.
Independence gave a new impetus to the development of science and in the mid-1990s, the Karakalpak Branch of the Academy of Sciences of the Republic of Uzbekistan became the support base of national scientific and pedagogical personnel for universities of the Republic, as well as the Karakalpak branch of the Academy of Agricultural Sciences of the Republic of Uzbekistan, the Research Institute of Clinical and Experimental Medicine of the Academy of Sciences of the Republic of Uzbekistan, the Karakalpak branch of the Uzbek Research Institute of Pedagogical Sciences, and other scientific institutions.

\section{LITERATURE}

1. Esbergenov H., Nurzhanov S. Son of the Fatherland. Nukus, 2018. P. 80.

2. Aymbetov K. Memory of the past days. Nukus, 2008. P. 169.

3. Central State Archive of the Republic of Karakalpakstan, fund 322, inventory 1, case 9, sheet 20.

4. Central State Archive of the Republic of Karakalpakstan, fund 322, inventory 1, case 5, sheet 80 .

5. Central State Archive of the Republic of Karakalpakstan, fund 322, inventory 1, case 9, sheet 186.

6. Kyzyl Karakalpakstan, 1936, March 28.

7. Soviet Karakalpakia, 1937, June.

8. Central State Archive of the Republic of Karakalpakstan, fund $R-551$, inventory 1 , case 6234, sheet 46.

9. Central State Archive of the Republic of Karakalpakstan, fund $R-551$, inventory 1 , case 6234 , sheet 48.

10. Tleuov R. Measures aimed at preserving the Aral Sea // Bulletin of the Karakalpak affiliate of the Academy of Sciences of the Uzbek Soviet Socialist Republic, 1974, No. 2. PP. 38-46.

11. Kabulov S. Possible consequences of the drying up of the Aral Sea. // Bulletin of the Karakalpak affiliate of the Academy of Sciences of the Uzbek Soviet Socialist Republic, 1974, No. 4. PP. 35-45.

12. Kamalov $S$. The year of our work // Bulletin of the Karakalpak affiliate of the Academy of Sciences of the Uzbek Soviet Socialist Republic, 1993, No. 1. P. 166.

13. Annual Meeting of Scientists of Karakalpakstan // Bulletin of the Karakalpak affiliate of the Academy of Sciences of the Uzbek Soviet Socialist Republic, 1994, No. 1. P. 3. 